\title{
Evaluation of pre-breeding reproductive tract scoring as a predictor of long term reproductive performance in beef heifers
}

\author{
D. E. Holm** , M. Nielen**, R. Jorritsma**, P. C. Irons* and P. N. Thompson* \\ *Department of Production Animal Studies, Faculty of Veterinary Science, University of Pretoria, Private \\ Bag X04, Onderstepoort, 0110, South Africa \\ **Department of Farm Animal Health, Faculty of Veterinary Medicine, Utrecht University, Yalelaan 7, \\ 3584 CL, Utrecht, Netherlands \\ ${ }^{\#}$ Corresponding author: email: dietmar.holm@up.ac.za Tel: +27125298218 Fax: +27125298315
}

\begin{abstract}
In a 7-year longitudinal study 292 Bovelder beef cows in a restricted breeding system in South Africa were observed from 1-2 d before their first breeding season, when reproductive tract scoring (RTS, scored from 1 to 5) was performed, until weaning their $5^{\text {th }}$ calves. The objective was to determine whether pre-breeding RTS in heifers is a valid tool to predict long-term reproductive performance. Outcomes measured were failure to show oestrus during the first 24 days of the first 50-day AI season (24-day anoestrus), failure to become pregnant during each yearly artificial insemination (AI) season (reproductive failure), number of days from the start of each AI season to calving, and number of years to reproductive failure. The effect of RTS on each outcome was adjusted for year of birth, pre-breeding age, BW and body condition score (BCS), and for 24-day anoestrus, bull, gestation length, previous days to calving and previous cow efficiency index, the latter two in the case of the $2^{\text {nd }}$ to the $5^{\text {th }}$ calving season. During their first
\end{abstract}


breeding season, heifers with RTS 1 and 2 combined were more likely to be in anoestrus for the first 24 days $(\mathrm{OR}=3.0,95 \% \mathrm{CI} 1.5,6.4, P=0.003)$, and were also more likely to fail to become pregnant even after adjusting for 24-day anoestrus (OR $=2.1,95 \%$ CI 1.1, 3.9, $P=0.025)$, compared to those with RTS 4 and 5 combined. Animals with RTS 1 and 2 combined were at increased risk of early reproductive failure compared to those with RTS 4 and 5 combined $(\mathrm{HR}=1.4,95 \%$ CI 1.0, 1.9, $P=0.045)$ although RTS was not associated with calving rate or days to calving after the second calving season. Low RTS at a threshold of 1 had consistent specificity of $\geq 94 \%$ for both 24 -day anoestrus and pregnancy failure, however its predictive value was lower in the age cohort with a higher prevalence of anoestrus. We conclude that RTS is a valid management tool for culling decisions intended to improve long-term reproductive success in a seasonal breeding system, by excluding heifers that are likely to fail to become pregnant or likely to calve late during their first calving season.

Keywords: beef cattle; culling; fertility; heifer selection; predictive ability; reproductive tract score

\section{INTRODUCTION}

Reproductive traits are 10 times more economically important than production traits in beef cows (Wiltbank, 1994). Restricted breeding and calving during the optimal season are key principles in good cow-calf management (Denham et al., 1991, Engelken et al., 1991). Proper management and selection of heifers (using body weight (BW), conformation, estimated breeding values, reproductive tract score (RTS) and pelvimetry) before breeding are essential to the success of such systems (Grass et al., 1982, Larson, 2005). 
The onset of puberty in heifers is initiated by a decrease in oestradiol receptors in the hypothalamus and pituitary, ending the prepubertal negative feed-back and resulting in the first LH surge and ovulation (Day et al., 1984, Day et al., 1987). This shift occurs at a specific critical BW (as a proportion of adult BW) and critical age which varies amongst animals (Pence et al., 2007). Various factors affect the age at puberty in individuals, and RTS provides an indirect measure of pubertal development (Andersen et al., 1991, Pence and BreDahl, 1998, Holm et al., 2009). Weaknesses of RTS include imperfect repeatability, subjectiveness and inconsistent associations with reproductive outcome (Rosenkrans and Hardin, 2003, Holm et al., 2009).

Short term reproductive performance may be predicted by RTS (Andersen et al., 1991, Pence et al., 2007, Holm et al., 2009) and we hypothesised that RTS may predict long-term survival in restricted bred heifers due to its association with pregnancy outcome and days to calving after first breeding, combined with reports that heifers calving early tend to calve early in subsequent seasons and have increased lifetime production (Lesmeister et al., 1973, Pence et al., 2007, Stevenson et al., 2008, Cushman et al., 2013). To the knowledge of the authors, a long-term study of the performance of heifers by RTS category has not been reported.

The objective of this study was to determine the usefulness of RTS as predictor of long-term reproductive performance.

\section{MATERIALS AND METHODS}

This was an observational study of 292 uniquely identified Bovelder cows born in either 2002 or 2003 (2002 and 2003 cohorts) that were followed from just prior to their first breeding season until they had weaned up to five calves. The farming system and 
breed type have been described previously (Paterson et al., 1980, Schoeman and Jordaan, 1998, Holm et al., 2008, 2009, 2014). In brief, the Bovelder is a South African composite beef breed, and Johannesburg Water Northern Farm is a semi-intensive system using irrigated ryegrass, kikuyu and clover pastures with additional maize or sorghum silage. The herd had been a closed female herd for more than 25 years prior to the onset of this study, and early breeding of heifers (breeding between 12 and 15 months of age) had been practiced for the same period of time prior to the onset of this study.

Reproductive tract scoring by trans-rectal palpation using a 5-point scale was performed by a single operator on all heifers either 1 or 2 days before the onset of their first breeding season (Andersen et al., 1991). Scores 4 and 5 were combined in the analyses, after assuming that both categories were pubertal at the time of scoring (Stevenson et al., 2008), and were used as the reference category in Cox proportional hazards and logistic regression models. It was further assumed that heifers with RTS 3 were peripubertal and that those with RTS 1 or 2 were prepubertal, which were also combined in the analyses (Stevenson et al., 2008). Body condition score (BCS) was determined at the same time by the same operator using a 9-point scale (Marston, 2005). For the purpose of regression models and survival analysis, BCS was categorized into 2 approximately equal sized categories: $\mathrm{BCS} \leq 6$ and $\mathrm{BCS} \geq 7$, because relatively few heifers were recorded to have $\mathrm{BCS}<6$ and $\mathrm{BCS}>7$. Farm management and staff were blinded to RTS data throughout the study.

Animals with parity $0,1,2$, and $\geq 3$ were managed in separate groups, assigned at the start of each yearly breeding season. Parity groups were managed in the same facility and inseminated by the same technician each year. The breeding season for heifers started 
on 15 October every year and consisted of 50 days of continuous visual oestrus observation, with once daily artificial insemination (AI) at $09 \mathrm{~h} 00$. The breeding season for cows started on 1 November and consisted of 60 days of oestrus observation and AI in a similar way. Inter-oestrus periods of nulliparous heifers ranged from 16 to 24 days (mean 20 days). Days to first oestrus was defined as either the days to first insemination if it resulted in a pregnancy, or the days to the first insemination that was followed by a normal (16 to 24 days) inter-oestrus interval, or if neither of the above occurred it was the days to the last insemination.

Seventeen AI bulls originating from the same herd were allocated to 10 to 30 heifers each, and the ratio decreased to 1 to 10 cows per AI bull by the fifth parity. Five to 10 days after the end of the AI period different clean-up bulls were placed with cows and heifers for a period of 42 days in a multisire system.

Pregnancy diagnoses (PD) were performed by transrectal palpation (Sheldon and Noakes, 2002) between 23 March and 26 April of every year. Artificial insemination records of cows were available to the veterinarian during pregnancy diagnosis to assist in the differentiation between AI and bull pregnancies. Animals that were not pregnant to the AI season were sold as soon as their status was known. Those that aborted, or that were confirmed pregnant to AI but failed to calve during the expected calving season, were also removed from the herd.

Data collected per cow during every AI and calving season included the following: bull allocated, first to fourth AI date, pregnancy diagnosis, abortion and culling dates, calving date, dystocia score, twinning data, calf gender, calf BW at birth and BW of the cow and calf at weaning. Cow efficiency index (CEI) determined at each 
weaning event was defined as the weaning weight of the calf corrected to an age of $205 \mathrm{~d}$ divided by the metabolic weight of the cow at weaning $\left(\mathrm{BW}^{0.75}\right)$ (Kleiber, 1947).

Days to pregnancy was defined as the days from the start of the AI season to the last insemination for animals that were confirmed pregnant after the end of the breeding season. Gestation length (GL) was defined as the number of days from the last recorded AI until calving. Data cleaning consisted of the following procedures to ensure that heifers and cows that aborted, or that became pregnant during the bull breeding season did not contribute any further data to the study: Animals with GL $<266$ days were either changed from "calved" to "aborted" if the birth weight of the calf was below $25 \mathrm{~kg}$ and the calf did not survive, otherwise an earlier conception date was assigned if this was available from the AI records, or else the GL data was removed if neither was possible. For animals with GL > 299 days the pregnancy diagnosis data was changed from pregnant to not pregnant, as we assumed that the cow did not conceive during the AI season, and all subsequent data of the cow (including following calving seasons) were removed. Alternatively, for animals with GL >299 days where the only recorded AI was early in the season and the calving date was too early for a bull pregnancy, the GL data was removed, in which case it was assumed that additional AI's performed were not recorded.

Days to calving was defined as the number of days from the start of the AI breeding season until each cow calved.

The study was terminated after the fifth intercalving interval had occurred for all remaining cows, which occurred in April 2009 and April 2010 for the 2002 and 2003 cohorts, respectively. 


\section{Analytical procedures}

Data were analysed using NCSS 2007 (NCSS, Kaysville, UT, USA) and STATA 11.1 (StataCorp, Texas, USA). Independent proportions, means and medians were compared using the Fisher exact test, ANOVA and Wilcoxon Rank-sum test, respectively. Medians were compared and reported where significant skewness occurred in at least one of the categories that were compared $(P<0.05$, Kolmogorov-Smirnov test). Standard deviations were provided with the means. Pregnancy proportions, proportions of different RTS categories, BW and age of heifers were compared between different AI bulls used during the first breeding season.

Reproductive tract score, being the variable of interest, was initially used in univariable models of days to calving and pregnancy outcome for the first to the fifth breeding season, and of 24-day anoestrus in the first breeding season for each heifer cohort as well as for the combined data. The individual effects of pre-breeding age, BW, BCS and GL, and also the preceding season's days to calving and CEI in the case of the second to fifth calving seasons, were also estimated, whereafter the effect of RTS on the outcome was adjusted for covariates that were significant $(P<0.05)$ predictors on their own, using multivariable models. Year of birth was forced into all models of the combined data, and AI bull was added as a random effect to the logistic regression models of pregnancy failure during the first AI season. Confounding effects were deemed to be present when inclusion of a potential confounding variable changed the regression coefficients or odds ratios of other variables in the model by more than $30 \%$, and such confounding variables were kept in the models (Dohoo et al, 2003a). The fit of the 
logistic regression models of pregnancy failure during the first AI season was evaluated using the Hosmer-Lemeshow goodness-of-fit test.

For the Cox regression model of years to reproductive failure, reproductive failure (the event of interest) was defined as a negative pregnancy diagnosis after the limited AI breeding season. Observations for reproductive failure were in other words performed once every year on the day of pregnancy diagnosis, and all data from other animals that had left the herd since the previous observation (or the start of the study in the case of the first pregnancy diagnosis) were interval censored to the current day of pregnancy diagnosis. Censored data included those from cows that had aborted their previous pregnancy, cows that died or cows that were culled for any other reason. Artificial insemination bull used during the first AI season was added as a shared frailty to the Cox regression model of years to reproductive failure, whereas the proportional hazards assumption of the model was evaluated using Schoenfeld residuals, and by evaluating the $\log$ cumulative hazards plot of the curves of the RTS categories. Data from cows that were still in the herd (and confirmed pregnant) at the study termination were right censored to the last observation (Dohoo et al, 2003b).

Sensitivity (Se), specificity (Sp) and positive predictive value $(\mathrm{PV}+)$ were calculated for the ability of low RTS (defined as a positive test result) to predict the status of either 24-day anoestrus or pregnancy failure (defined as the presence of the condition tested for). Two thresholds for determining test positive status were evaluated: RTS 1 and RTS 2. 


\section{RESULTS}

The 2002 cohort of heifers was older (mean age $428.6 \pm 19.9$ days vs. $420.8 \pm 14.7$ days, $P<0.001$ ), but lighter (mean BW $315.8 \pm 26.4 \mathrm{~kg}$ vs. $324.0 \pm 25.9 \mathrm{~kg}, P=0.010$ ) than those born in 2003 at the start of their first breeding season. In the 2002 cohort there were low but significant correlations between pre-breeding age and BW (Pearson's $r=$ $0.32, P<0.001)$, age and RTS $(r=0.29, P<0.001)$, BCS and BW $(r=0.30, P<0.001)$ and BCS and age $(r=0.21, P=0.005)$. In the 2003 cohort none of the pre-breeding variables were significantly correlated. In the 2002 cohort fewer heifers were prepubertal (RTS 1 or 2$)$ than in the 2003 cohort (56/184 vs. $46 / 108, P=0.042)$ and more heifers tended to be pubertal $(75 / 184$ vs. $32 / 108, P=0.060)$.

In the 2002 cohort, fewer heifers had inter-oestrus periods shorter than 16 days during the first breeding season than in the 2003 cohort (32/106 vs. $36 / 73, P=0.012$ ), whereas the proportion of inter-oestrus periods longer than 24 days was similar (19/106 vs. $7 / 73, P=0.136)$. Median days to first oestrus, to first pregnancy and to first calving

Table 1. Outcomes of different categories of pre-breeding RTS after the 50-day heifer breeding season, by year of birth.

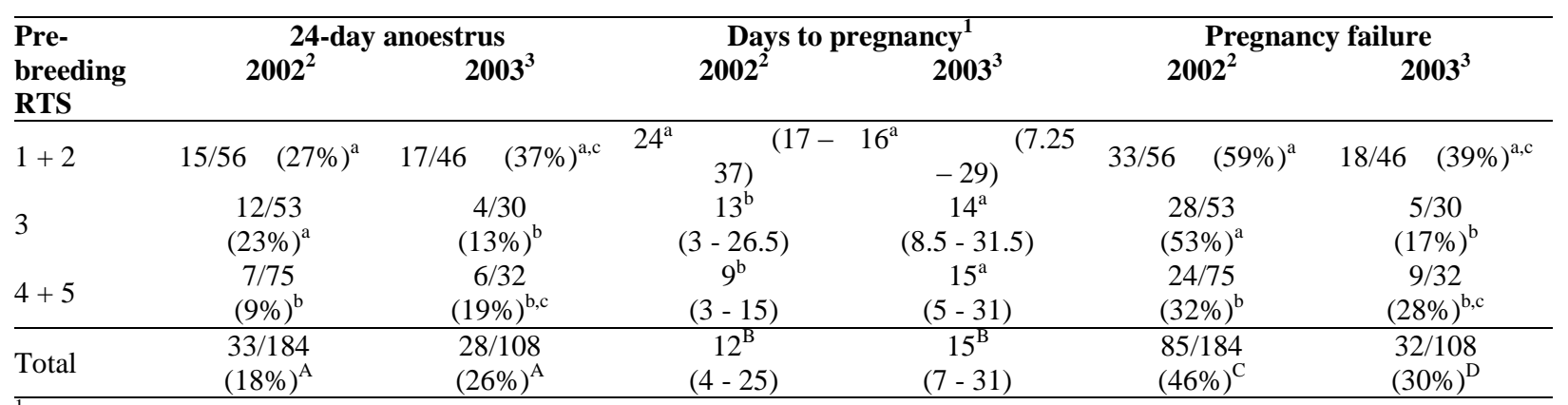

${ }^{\mathrm{T}}$ Median (interquartile range)

${ }^{2} 2002$ birth cohort

${ }^{3} 2003$ birth cohort

${ }^{\mathrm{a}, \mathrm{b}}$ Proportions or medians within columns with different superscripts differ significantly $(P<0.05)$

${ }^{\mathrm{A}, \mathrm{B}}$ Proportions or medians within rows with different superscripts differ significantly $(P<0.05)$ 
RTS long-term usefulness and predictive value

decreased with increasing RTS category in the 2002 cohort but this was not the case for the 2003 cohort (Table 1).

Heifers with low RTS had higher rates of 24-day anoestrus and pregnancy failure when compared to those with higher RTS (Table 1). Lower RTS was independently associated with an increased odds of 24-day anoestrus in both years (Table 2). None of the other variables was independently associated with 24-day anoestrus even when RTS was removed from the models $(P>0.05)$, whereas most of the odds ratios presented in Table 2 changed by more than $30 \%$ when RTS was removed from the models.

Table 2. Multivariable logistic regression models of factors associated with 24-day anoestrus, for the two birth cohorts separately and combined.

\begin{tabular}{|c|c|c|c|c|c|c|c|c|c|c|c|c|}
\hline \multirow{3}{*}{$\frac{\text { Predictor }}{\text { RTS } 1+2}$} & \multicolumn{4}{|c|}{$2002^{1}$} & \multicolumn{4}{|c|}{$2003^{2}$} & \multicolumn{4}{|c|}{ Combined $^{3}$} \\
\hline & $\mathbf{O R}^{4}$ & & & $P$ & $\mathbf{O R}^{4}$ & & & $P$ & $\mathbf{O R}^{4}$ & & & $P$ \\
\hline & 3.7 & 1.3 & 10.4 & 0.012 & 2.5 & 0.8 & 7.5 & 0.098 & 3.0 & 1.5 & 6.4 & 0.003 \\
\hline RTS 3 & 2.4 & 0.9 & 6.8 & 0.094 & 0.7 & 0.2 & 2.7 & 0.577 & 1.5 & 0.7 & 3.5 & 0.302 \\
\hline RTS $4+5$ & 1.0 & - & - & - & 1.0 & - & - & - & 1.0 & - & - & - \\
\hline $\mathrm{BW}($ per $10 \mathrm{~kg})$ & 1.0 & 0.9 & 1.2 & 0.848 & 1.0 & 0.8 & 1.2 & 0.721 & 1.0 & 0.9 & 1.1 & 0.919 \\
\hline Age (w) & 1.0 & 0.9 & 1.2 & 0.649 & 0.9 & 0.7 & 1.1 & 0.342 & 1.0 & 0.9 & 1.1 & 0.923 \\
\hline BCS 6 vs 7 & 1.6 & 0.7 & 3.7 & 0.244 & 0.9 & 0.4 & 2.4 & 0.876 & 1.3 & 0.7 & 2.3 & 0.395 \\
\hline $\begin{array}{l}\text { Year of birth } \\
2002 \text { vs } 2003\end{array}$ & - & - & - & - & - & - & - & - & 0.8 & 0.4 & 1.4 & 0.388 \\
\hline
\end{tabular}

12002 birth cohort

${ }^{2} 2003$ birth cohort

${ }^{3} 2002$ and 2003 birth cohorts combined

${ }^{4}$ Odds ratio

Although not the case for the 2003 cohort, all heifers in the study with RTS 1 and 2 combined (compared to RTS 4 and 5 combined) were more likely to fail to become pregnant during their first AI season, after adjusting for 24-day anoestrus, pre-breeding BW and age (Table 3). Even when excluding those heifers in anoestrus during the entire 50-day AI season, heifers with RTS 1 and 2 combined were more likely to fail to become pregnant than those with RTS 4 and 5 combined $(\mathrm{OR}=1.9, P=0.043)$. The random effect of AI bull in the logistic regression model of pregnancy failure during the first AI 
RTS long-term usefulness and predictive value

Table 3. Multivariable logistic regression models of factors associated with pregnancy failure after the first 50-day AI season, for the two birth cohorts separately and combined.

\begin{tabular}{|c|c|c|c|c|c|c|c|c|c|c|c|c|}
\hline \multirow{3}{*}{$\frac{\text { Predictor }}{\text { RTS } 1+2}$} & \multicolumn{4}{|c|}{$2002^{1}$} & \multicolumn{4}{|c|}{$2003^{2}$} & \multicolumn{4}{|c|}{ Combined $^{3}$} \\
\hline & $\mathbf{O} \mathbf{R}^{4}$ & \multicolumn{2}{|c|}{$95 \% \mathrm{CI}$} & \multirow{2}{*}{$\frac{\boldsymbol{P}}{0.009}$} & \multirow{2}{*}{$\begin{array}{c}\mathbf{O R}^{4} \\
1.0\end{array}$} & \multicolumn{2}{|c|}{$95 \% \mathrm{CI}$} & \multirow{2}{*}{\begin{tabular}{c|}
$\boldsymbol{P}$ \\
0.942
\end{tabular}} & \multirow{2}{*}{$\frac{\mathbf{O R}^{4}}{2.1}$} & \multicolumn{2}{|c|}{$95 \% \mathrm{CI}$} & \multirow{2}{*}{$\frac{\boldsymbol{P}}{0.025}$} \\
\hline & 2.8 & 1.3 & 6.0 & & & 0.3 & 3.3 & & & 1.1 & 3.9 & \\
\hline RTS 3 & 2.2 & 1.0 & 4.6 & 0.041 & 0.5 & 0.1 & 2.0 & 0.342 & 1.4 & 0.8 & 2.7 & 0.279 \\
\hline RTS $4+5$ & 1.0 & - & - & - & 1.0 & - & - & - & 1.0 & - & - & - \\
\hline $\mathrm{BW}$ (per 10kg) & 0.9 & 0.8 & 1.0 & 0.149 & 1.0 & 0.8 & 1.2 & 0.704 & 0.9 & 0.8 & 1.0 & 0.179 \\
\hline Age (w) & 1.0 & 0.9 & 1.2 & 0.440 & 1.0 & 0.8 & 1.3 & 0.997 & 1.0 & 0.9 & 1.1 & 0.704 \\
\hline $\begin{array}{l}\text { 24-day } \\
\text { anoestrus }\end{array}$ & 1.9 & 0.9 & 4.4 & 0.105 & 11.4 & 4.0 & 32.3 & $<0.001$ & 4.2 & 2.2 & 8.0 & $<0.001$ \\
\hline $\begin{array}{l}\text { Year of birth } \\
2002 \text { vs } 2003\end{array}$ & - & - & - & - & - & - & - & - & 2.5 & 1.4 & 4.5 & 0.001 \\
\hline & $\begin{array}{l}{ }^{1} 200 \\
{ }^{2} 200 \\
{ }^{3} 200 \\
{ }^{4} \mathrm{Od}\end{array}$ & $\begin{array}{l}\text { th ce } \\
\text { th ce } \\
\text { d } 20 \\
\text { io }\end{array}$ & th & com & & & & & & & & \\
\hline
\end{tabular}


RTS long-term usefulness and predictive value

season was not significant $(P=1.000)$, and the fit of the logistic regression model of pregnancy failure after the first AI season was adequate (Hosmer-Lemeshow $P=0.129$ ).

Heifers with RTS 1 and 2 combined had a lower calving rate and calved later during the first calving season than those with RTS 4 and 5 combined (Table 4). In the second calving season, the remaining heifers with initial RTS 1 and 2 combined tended to have a lower calving rate than those with RTS 4 and 5 combined $(P=0.068)$, and they calved later than those with RTS 3 (Table 4). From the third calving season onwards, no differences in calving rates and days to calving between RTS categories in animals that remained in the herd were evident (Table 4).

Table 4. Calving rate and median days to calving, by calving season, for different pre-breeding RTS categories.

\begin{tabular}{|c|c|c|c|c|c|c|c|c|c|c|}
\hline \multirow{2}{*}{$\begin{array}{l}\text { Pre- } \\
\text { breeding } \\
\text { RTS }\end{array}$} & \multicolumn{2}{|c|}{ First $^{1}$} & \multicolumn{2}{|c|}{ Second $^{1}$} & \multicolumn{2}{|c|}{ Third $^{1}$} & \multicolumn{2}{|c|}{ Fourth $^{1}$} & \multicolumn{2}{|c|}{ Fifth $^{1}$} \\
\hline & $\begin{array}{l}\text { calv } \\
\text { rate }^{2}\end{array}$ & d to calv ${ }^{3}$ & $\begin{array}{l}\text { calv } \\
\text { rate }\end{array}$ & d to calv & $\begin{array}{l}\text { calv } \\
\text { rate }\end{array}$ & d to calv & $\begin{array}{l}\text { calv } \\
\text { rate }\end{array}$ & d to calv & $\begin{array}{l}\text { calv } \\
\text { rate }\end{array}$ & d to calv \\
\hline $1+2$ & $\begin{array}{l}48 / 102 \\
(47 \%)^{\mathrm{a}}\end{array}$ & $\begin{array}{c}299^{\mathrm{a}} \\
(288-313)\end{array}$ & $\begin{array}{c}31 / 48 \\
(65 \%)^{\mathrm{a}}\end{array}$ & $\begin{array}{c}306^{\mathrm{a}} \\
(298-314)\end{array}$ & $\begin{array}{c}24 / 31 \\
(77 \%)^{\mathrm{a}}\end{array}$ & $\begin{array}{c}303^{\mathrm{a}} \\
(297-325.5)\end{array}$ & $\begin{array}{c}16 / 24 \\
(67 \%)^{\mathrm{a}}\end{array}$ & $\begin{array}{c}301.5^{\mathrm{a}} \\
(295-314)\end{array}$ & $\begin{array}{c}10 / 16 \\
(63 \%)^{\mathrm{a}}\end{array}$ & $\begin{array}{c}312.5^{\mathrm{a}} \\
(297-327.5)\end{array}$ \\
\hline 3 & $\begin{array}{c}45 / 83 \\
(54 \%)^{\mathrm{a}, \mathrm{b}}\end{array}$ & $\begin{array}{c}298^{\mathrm{a}, \mathrm{b}} \\
(289-312)\end{array}$ & $\begin{array}{l}31 / 45 \\
(69 \%)^{\mathrm{a}}\end{array}$ & $\begin{array}{c}293^{\mathrm{b}} \\
(289-311)\end{array}$ & $\begin{array}{c}21 / 31 \\
(68 \%)^{\mathrm{a}}\end{array}$ & $\begin{array}{c}302^{\mathrm{a}} \\
(290.5-313.5)\end{array}$ & $\begin{array}{c}16 / 21 \\
(76 \%)^{\mathrm{a}}\end{array}$ & $\begin{array}{c}301.5^{\mathrm{a}} \\
(294-322)\end{array}$ & $\begin{array}{c}10 / 16 \\
(63 \%)^{\mathrm{a}}\end{array}$ & $\begin{array}{c}304^{\mathrm{a}} \\
(295-324)\end{array}$ \\
\hline $4+5$ & $\begin{array}{l}69 / 107 \\
(64 \%)^{b}\end{array}$ & $\begin{array}{c}292^{\mathrm{b}} \\
(286-304)\end{array}$ & $\begin{array}{l}55 / 69 \\
(80 \%)^{\mathrm{a}}\end{array}$ & $\begin{array}{c}301^{\mathrm{a}, \mathrm{b}} \\
(294-315)\end{array}$ & $\begin{array}{c}36 / 55 \\
(65 \%)^{\mathrm{a}}\end{array}$ & $\begin{array}{c}310^{\mathrm{a}} \\
(298-322)\end{array}$ & $\begin{array}{c}24 / 36 \\
(67 \%)^{\mathrm{a}}\end{array}$ & $\begin{array}{c}305.5^{\mathrm{a}} \\
(296-315)\end{array}$ & $\begin{array}{c}16 / 24 \\
(67 \%)^{\mathrm{a}}\end{array}$ & $\begin{array}{c}303^{\mathrm{a}} \\
(298-322.5)\end{array}$ \\
\hline
\end{tabular}

${ }^{1}$ First to fifth calving season

${ }^{2}$ Calving rate as a proportion of the total number of heifers or cows bred

${ }^{3}$ Median days to calving (interquartile range)

${ }^{\mathrm{a}, \mathrm{b}}$ Proportions or medians within columns with different superscripts differ significantly $(P<0.05)$

In the Cox regression model of days to first calving, heifers with RTS 1 and 2 combined tended to be less likely to calve early in their first calving season than those with RTS 4 and 5 combined, adjusted for pre-breeding BW and age $(\mathrm{HR}=0.7,95 \% \mathrm{CI}=$ $0.5-1.0, P=0.082)$. Neither pre-breeding BW, age, BCS, RTS, previous days to calving nor previous CEI was consistently associated with pregnancy failure or days to calving in the second to fifth calving seasons. In univariable Cox regression models of years to reproductive failure, 24-day anoestrus during the first breeding season was the only 
consistent predictor in both birth cohorts $(P=0.036$ and $P<0.001$ for 2002 and 2003, respectively). When only pre-breeding measures were considered in a multivariable Cox regression model, RTS categories 1 and 2 combined (relative to RTS 4 and 5), and prebreeding BW predicted years to reproductive failure independently after adjusting for year of birth (Table 5, Figure 1). The model did not violate the proportional hazards

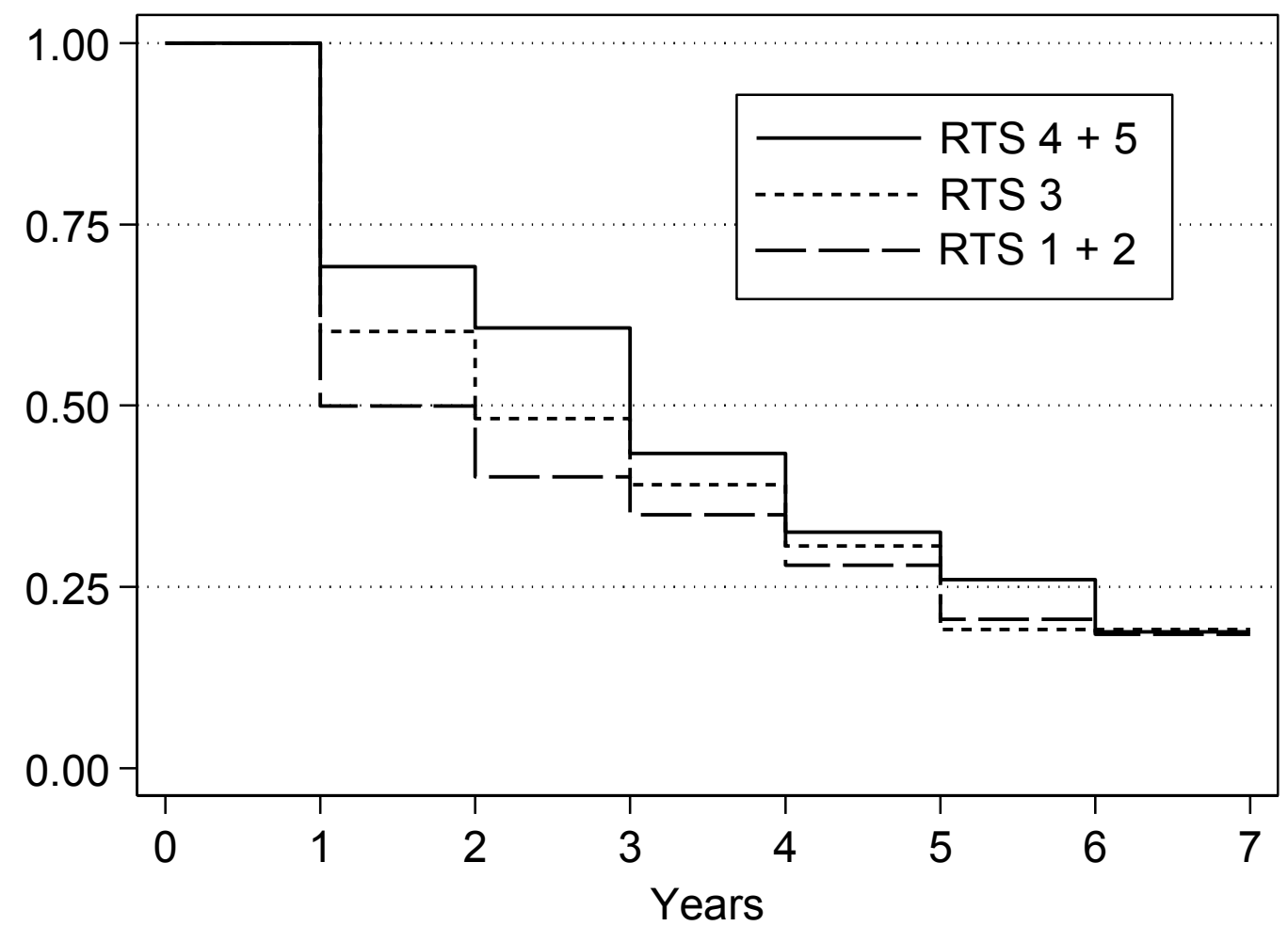

Figure 1. Kaplan-Meier survival curves for heifers with different pre-breeding RTS categories.

Table 5. Multivariable Cox regression model of factors associated with the number of years to reproductive failure.

\begin{tabular}{|c|c|c|c|c|}
\hline \multirow[b]{2}{*}{ Predictor } & \multicolumn{4}{|c|}{ Years to reproductive failure } \\
\hline & $\mathbf{H R}^{1}$ & & & $\boldsymbol{P}$ \\
\hline RTS $1+2$ & 1.4 & 1.0 & 1.9 & 0.045 \\
\hline RTS 3 & 1.3 & 0.9 & 1.8 & 0.184 \\
\hline RTS $4+5$ & 1.0 & - & - & - \\
\hline $\mathrm{BW}($ per $10 \mathrm{~kg})$ & 0.9 & 0.9 & 1.0 & 0.043 \\
\hline Year of birth 2002 & 1.4 & 1.1 & 1.9 & 0.020 \\
\hline
\end{tabular}

${ }^{1}$ Hazard ratio 
RTS long-term usefulness and predictive value

assumption $(P=0.326)$, and $\log$ cumulative hazards plots of the RTS categories remained reasonably parallel up to year 4 . The bull assigned during the first AI season did not have a significant effect as shared frailty $(P=0.444)$.

Reproductive tract score 1 had a Sp of at least $94 \%$ for 24-day anoestrus or pregnancy failure during the first breeding season. In other words, had heifers with RTS 1 been culled from the herd, $94 \%$ of heifers that were observed in oestrus during the first 24 days or that became pregnant (equating to absence of the conditions tested for) would have been retained in the herd due to the fact that they had a RTS higher than 1 . Increasing the cut-off to RTS 2 decreased the Sp by between 18 and 32\%. The PV+ of low RTS for 24-day anoestrus and pregnancy failure varied, depending on the average pregnancy results in that year (Table 6).

Table 6. Ability of low RTS to predict anoestrus in the first 24 days of the breeding season or to predict failure to become pregnant during the first 50-day AI season, by birth cohort.

\begin{tabular}{|c|c|c|c|c|c|c|c|}
\hline Outcome & $\begin{array}{c}\text { Year of } \\
\text { birth }\end{array}$ & $\begin{array}{c}\text { True } \\
\text { incidence }\end{array}$ & RTS & Culling $\%^{1}$ & $\mathrm{Se}^{2}$ & $\mathrm{Sp}^{3}$ & $\mathbf{P V}+{ }^{4}$ \\
\hline \multirow{4}{*}{$\begin{array}{l}\text { 24-day } \\
\text { anoestrus }\end{array}$} & \multirow{2}{*}{2002} & \multirow{2}{*}{$18 \%$} & 1 & $7 \%$ & 0.12 & 0.94 & 0.31 \\
\hline & & & $1-2$ & $30 \%$ & 0.42 & 0.72 & 0.25 \\
\hline & \multirow{2}{*}{2003} & \multirow{2}{*}{$26 \%$} & 1 & $11 \%$ & 0.29 & 0.95 & 0.67 \\
\hline & & & $1-2$ & $43 \%$ & 0.64 & 0.65 & 0.39 \\
\hline \multirow{4}{*}{$\begin{array}{l}50 \text {-day } \\
\text { pregnancy } \\
\text { failure }\end{array}$} & \multirow{2}{*}{2002} & \multirow{2}{*}{$46 \%$} & 1 & $7 \%$ & 0.09 & 0.95 & 0.62 \\
\hline & & & $1-2$ & $30 \%$ & 0.39 & 0.77 & 0.59 \\
\hline & \multirow{2}{*}{2003} & \multirow{2}{*}{$30 \%$} & 1 & $11 \%$ & 0.25 & 0.95 & 0.67 \\
\hline & & & $1-2$ & $43 \%$ & 0.56 & 0.63 & 0.39 \\
\hline
\end{tabular}

${ }^{1}$ Percentage animals that would be culled based on low RTS

${ }^{2}$ Sensitivity

${ }^{2}$ Specificity

${ }^{3}$ Positive predictive value

\section{DISCUSSION}

\section{RTS as predictor of long-term reproductive performance}

In heifers born in both years RTS was associated with 24-day anoestrus independent of pre-breeding BW, age or BCS. This supports the theory that BW and age 
when puberty is reached varies between animals (Pineda et al, 2003), even in a uniform group such as the animals in our study, making RTS a unique management tool to identify heifers that have not reached puberty by the start of the first breeding season (Anderson et al., 1990). In this study RTS predicted the proportion of heifers pregnant and the time to pregnancy during the first breeding season, and to a lesser degree during the second breeding season (Table 4). Other researchers demonstrated that cows that calve early during the first calving season, calve early during subsequent seasons as well and have increased lifetime production (Lesmeister et al., 1973, MacGregor and Casey, 1999, Pence et al., 2007, Stevenson et al., 2008). In a previous report (Holm et al., 2009) we therefore hypothesised that heifers with higher RTS before the start of the first breeding season are likely to calve early during subsequent breeding seasons compared to their herd mates with lower RTS. It was further hypothesised that such heifers will have increased survival in a seasonal breeding system with a strict culling policy based on reproductive failure. In the current study, RTS marginally predicted the number of years to reproductive failure independent of other pre-breeding measures (Table 5). However, in our data RTS was not a predictor of pregnancy rate or days to calving in the remaining animals from the third to fifth calving season, and the effect of RTS on long-term reproductive failure appears to be determined mostly by the outcome of the first breeding season and to some extent the effect on the second breeding season (Table 4). A limitation in our data, however, was that different inseminators were used for different parity groups, therefore confounding by inseminator cannot be excluded. In our data, days to calving during the second and subsequent calving seasons did not depend on days to calving of any of the preceding calving seasons $(P>0.05)$, in contrast to previous 
findings (Lesmeister et al., 1973, Pence et al., 2007, Stevenson et al., 2008, Cushman et al., 2013).

It may be that the strict application of culling after reproductive failure in this system reduced variability in the animals surviving to subsequent seasons to the point that animals with inherently lower reproductive ability were no longer present after the first two breeding seasons, and that those animals with low RTS that survived until the third to fifth breeding seasons represent misclassifications in RTS. Of the original 102 animals with RTS 1 and 2 combined in this study, only 16 survived to the start of their fifth breeding season, which may have resulted in an inability to draw any further conclusions in this study.

Antral follicle count, being a proxy for follicular reserve (Ireland et al., 2011) has been shown to have a significant association with ovarian size (Cushman et al., 2009), and it was expected that the RTS system may predict long-term survival due to the potential association with follicular reserve. It appears from our analyses that in the 2002 cohort, RTS had the ability to predict pregnancy failure not only due to the failure to be observed in oestrus during the first $24 \mathrm{~d}$ of the breeding season, but also due to other, unknown factors. The other factors leading to pregnancy failure in this breeding season could not be determined though, making it difficult to speculate about the association between RTS and fertility which lies beyond cyclicity. Further studies are needed to test the hypothesis that heifers with lower RTS have inferior reproductive performance over the long term, and in non-seasonal systems. 


\section{Factors affecting the predictive ability of RTS}

The lack of clear correlations between pre-breeding measures in the 2003 cohort, as well as the fact that the 2003 cohort was heavier despite being younger than the 2002 cohort prior to breeding suggests different culling practices and growth rates in the heifers of the two age cohorts.

The higher proportion of short ( $<16$ days) inter-oestrus periods recorded in the first breeding season of the 2003 cohort compared to the 2002 cohort suggests that either there were more heifers with truly short inter-oestrus intervals in the 2003 cohort, or oestrus observation accuracy differed between years. Although not significantly different, the proportion of longer (> 24 days) inter-oestrus periods recorded in the 2003 cohort was nominally lower. We therefore assume that oestrus observation was most likely more sensitive and less specific in the 2003 cohort than in the 2002 cohort.

Lower RTS scores were generally associated with increased rates of 24-day anoestrus in both years of birth in this study. In the 2003 cohort, however, the higher rate of 24-day anoestrus was not well predicted by RTS, when compared to the same results for the 2002 cohort. In particular, heifers with RTS 4 and 5 in the 2003 cohort had an unexpectedly high rate of anoestrus, despite the fact that oestrus observation sensitivity (Se) was likely higher. We therefore conclude that the incidence of true anoestrus was higher in the 2003 than in the 2002 cohort. This may have been caused by the younger age of the 2003 cohort or by differences in environmental or management factors during the first breeding seasons of the two cohorts (Larson, 2005).

The uniformity of the 2003 cohort due to apparently appropriate management and pre-selection may have influenced our ability to show significant differences between 
animals in this group. Although the same veterinarian applied RTS in the two cohorts, it is possible that due to the subjective nature of the RTS system systematic operator bias between the two age cohorts influenced the scores allocated. In addition to this, different growth rates between the two cohorts may have led to different rates of sexual development that occurred after the application of RTS (Gasser, 2006). The higher prebreeding growth rate of the 2003 cohort (evidenced by their higher BW and lower age) suggests that if this trend continued into the first AI season, animals with RTS scores 2 and 3 may have developed significantly between the application of RTS and the end of the AI season.

The incidence of 24-day anoestrus was relatively low in the 2002 cohort, and it appears that anoestrus was mostly as a result of animals not having reached puberty at the onset of breeding, as indicated by the ability of RTS 1, 2 and 3 to predict anoestrus relative to scores 4 and 5. Although other factors leading to reproductive failure seem to have existed in the first breeding season of the 2002 cohort, potential confounding due to differing oestrus observation accuracy between the two years cannot be ruled out.

In the 2003 cohort RTS did not predict pregnancy failure as accurately as in the 2002 cohort. Also, in the 2003 cohort RTS did not predict pregnancy failure after correction for anoestrus. It is therefore assumed that other factors leading to animals failing to show oestrus during the first $24 \mathrm{~d}$ of the breeding season, and that were not measurable by RTS, existed in this cohort. These may have included management factors such as nutrition, as well as other environmental factors such as weather (Larson, 2005). However, in this cohort there was a very strong association between 24-day anoestrus and pregnancy failure, and it appears that there were very few other factors leading to 
pregnancy failure except for heifers that were not observed in oestrus. It is thus concluded that other factors than pubertal stage leading to anoestrus, and therefore indirectly to pregnancy failure, resulted in RTS not being able to predict pregnancy failure as accurately as in the heifers born in 2002.

The Sp of RTS for 24-day anoestrus was coincidentally very similar to the Sp at the same cut-off for 50-day pregnancy failure within year of birth, and also similar between years of birth (Table 6). However, the PV+ of RTS for pregnancy failure in the 2002 cohort was higher than the PV+ for 24-day anoestrus at the same RTS threshold. This occurred due to the higher incidence of pregnancy failure compared to 24-day anoestrus (Dohoo et al., 2003b), combined with the apparent ability of RTS to predict pregnancy failure independent of its association with cyclicity in this age cohort.

For the 2003 cohort the Se, Sp and PV+ of low RTS were very similar for 24-day anoestrus and pregnancy failure, and this happened where the true prevalence of anoestrus during the first 24 days was similar to the true prevalence of pregnancy failure after the first 50-day breeding season. It seems thus that the ability of RTS to predict pregnancy outcome is firstly influenced by the true prevalence of anoestrus, and secondly by other factors causing pregnancy failure.

Our data did not clearly explain reasons for misclassifications in RTS, however stage of the oestrus cycle at the time of scoring should be considered a potentially important factor leading to false low scores for animals that are in metoestrus at the time of scoring. This is a time of the oestrus cycle when the new CL after ovulation may still be small and embedded within the ovary, and therefore not easily palpable (Rosenkrans and Hardin, 2003, Fernández Sánches, 2008), particularly in the case of peripubertal 
heifers. Simultaneously, the new follicular wave after ovulation is developing, with the probability of detecting palpable follicles being low (Fernández Sánches, 2008).

When RTS is applied in practice, these factors need to be considered, and culling rates need to be adjusted accordingly: Firstly, in herds where a relatively high proportion of heifers are pre-puberal at the start of the breeding season, or where a high proportion of heifers are expected to fail to become pregnant, higher culling rates are warranted due to the improved accuracy of RTS that can be expected. Secondly, in herds where an unexpected high proportion of heifers have low RTS scores, low scoring animals should be scored again after 7 days to rule out false positive tests that occurred due to stage of the oestrus cycle.

\section{CONCLUSIONS}

Reproductive tract scoring is a valid management tool for culling of beef heifers in anoestrus at the start of a seasonal breeding system. Culling based on pre-breeding RTS enhances long-term reproductive success of the herd by the effect on the pregnancy outcome of the first two breeding seasons.,

\section{ACKNOWLEDGEMENTS}

The authors thank Roger and Lynette Wood of Johannesburg Water's Northern Farm for providing the animals, facilities and farm data, and Reinette van Reenen and Daleen Anderson for assistance with data capture.

This research was performed under protocol no V089/13, as approved by the Animal use and Care Committee of the University of Pretoria. 


\section{LITERATURE CITED}

Andersen, K. J., LeFever, D. G., Brinks, J. S., K. G. 1991. The use of reproductive tract scoring in beef heifers. Agri-Practice 12(4):19-26.

Cushman, R. A., Kill, L. K., Funston, R. N., Mousel E. M., Perry, G. A. 2013. Heifer calving date positively influences calf weaning weights through six parturitions. J. Anim. Sci. 91:4486-4491.

Day, M. L., Imakawa, K., Garcia-Winder, M., Zalesky, D. D., Schanbacher, B. D., Kittok, R. J., Kinder, J. E. 1984. Endocrine mechanisms of puberty in heifers: Estradiol negative feedback regulation of luteinizing hormone secretion. Biol. Reprod. 31:332-341.

Day, M. L., Imakawa, K., Wolfe, P. L., Kittok, R. J., Kinder, J. E. 1987. Endocrine mechanisms of puberty in heifers. Role of hypothalamo- pituitary estradiol receptors in the negative feedback of estradiol on luteinizing hormone secretion. Biol. Reprod. 37:1054-1065.

Denham, S. C., Larson, R. E., Boucher J., Adams, E. L. 1991. Structure and behavior of a deterministic model of reproductive performance in beef cattle. Agric. Systems $35: 21-36$

Dohoo, I., Martin, W., Stryhn, H. 2003a. Confounder bias: Analytic control and matching. In: Dohoo, I., Martin, W., Stryhn, H. Veterinary epidemiologic research: 235-271. AVC Inc., Charlottetown, Canada.

Dohoo, I., Martin, W., Stryhn, H. 2003b. Modelling survival data. In: Dohoo, I., Martin, W., Stryhn, H. Veterinary epidemiologic research: 409-458. AVC Inc., Charlottetown, Canada.Engelken, T. J., Spire, M. F., Simms, D. D., McWhirter, J. 
D. 1991. Management practices that increase beef herd profitability. Vet. Med. $86: 851-857$.

Fernández Sánches, M. 2008. The ooestrus cycle of the cow: a photographic atlas. Diseño y Comunicación Servet, Zaragoza, Spain.

Gasser, C. L. 2006. Induction of precocious puberty in heifers III: hastened reduction of oestradiol negative feedback on secretion of lutenizing hormone. J. Anim. Sci. 84(8): 2050-2056.

Grass, J. A., Hansen, P. J., Rutledge, J. J., Hauser, E. R. 1982. Genotype x environment interactions on reproductive traits in bovine females. I. Age at puberty as influenced by breed, breed of sire, dietary regimen and season. J. Anim. Sci. $55: 1441-1457$

Holm, D. E., Thompson, P. N., Irons, P. C. 2008. The economic effects of an oestrus synchronization protocol using prostaglandin in beef heifers. Therio. 70:15071515

Holm, D. E., Thompson, P. N., Irons, P. C. 2009. The value of reproductive tract scoring as a predictor of fertility and production outcomes in beef heifers. J. Anim. Sci. $87: 1934-40$

Holm, D. E., Webb, E. C., Thoompson, P. N. 2014. A new application of pelvis area data as culling tool to aid in the management of dystocia in heifers. J. Anim. Sci. 92:2296-2303

Kleiber, M. 1947. Body size and metabolic rate. Physiol. Rev. 27:511-541 
RTS long-term usefulness and predictive value

Larson, R. L. 2005. Replacement heifers. In: Chenoweth, P. J., Sanderson, M. W. Beef practice: cow-calf production medicine: 127 - 150 Blackwell Publishing, Ames, Iowa.

Lesmeister, J. L., Burfening, P. J., Blackwell, R. L. 1973. Date of first calving in beef cows and subsequent calf production. J. Anim. Sci. 36:1-6

Marston, T. T. 2005. Beef cowherd nutrition and management. In: Chenoweth, P. J., Sanderson, M. W. Beef practice; Cow-calf production medicine: 89 - 108 Blackwell Publishing, Ames, Iowa.

Paterson A. G., Venter, H. A. W., Harwin, G. O. 1980. Preweaning growth of British, Bos Indicus, Charolais and dual purpose type cattle under intensive pasture conditions. S. Afr. J. Anim. Sci. 10:125 - 34

Pence, M. D., BreDahl, R. 1998. Clinical use of reproductive tract scoring to predict pregnancy outcome. Pages 259-260 in Proc. 31st Ann. Conf. AABP, Spokane, Washington.

Pence, M., Ensley, D., Berghaus, R., Rossi, J., Wilson, T., Cannon, P. T. 2007. Improving Reproductive Efficiency Through the Use of Reproductive Tract Scoring in a Group of Beef Replacement Heifers. Bov. Prac. 41(1):35-40.

Pineda, M. H. 2003. Female reproductive system. In: Pineda, M. H., Dooley, M.P. (eds) McDonald's Veterinary Endocrinology and Reproduction. Iowa State Press, Iowa. Pages 283-321

Rosenkrans, K. S., Hardin, D. K. 2003. Repeatability and accuracy of reproductive tract scoring to determine pubertal status in beef heifers. Therio. 59(5-6):1087-1092. 
Schoeman, S. J., Jordaan, G. G. 1998. Animal x testing environment interaction on postweaning liveweight gains of young bulls. Aust. J. Agric. Res. 49:607 - 12

Sheldon, M., Noakes, D. 2002. Pregnancy diagnosis in cattle. In Pract. 24(6): 310-317.

Stevenson, J. L., Rodrigues, J. A., Braga, F. A., Bitente, S., Dalton, J. C, Santos J. E. P., Chebel, R. C. 2008. Effect of breeding protocols and reproductive tract score on reproductive performance of dairy heifers and economic outcome of breeding programs. J. Dairy Sci. 91:3424-3438

Wiltbank, J. N. 1994. Challenges for improving calf crop. Pages 1-53 in Factors Affecting Calf Crop. M. J. Fields and R. J. Sand, eds. CRC Press. 